\title{
Evaluation of female prognostic factors influencing pregnancy rate after intrauterine insemination with controlled ovarian hyper stimulation in infertile couples in a tertiary care hospital
}

\author{
Shirly Kurian ${ }^{1}$, Jill Mathew ${ }^{2}$, Sarat Battina ${ }^{3}$, Nisha BS $^{4}$
}

\author{
${ }^{1}$ Assistant Professor, Department of Obstetrics and Gynaecology, Mount Zion Medical College, Chayalode, \\ Pathanamthitta, Kerala, India \\ ${ }^{2}$ Assistant Professor, Department of Pharmacology, Believer's Church Medical College, Thiruvalla, Kerala, India \\ ${ }^{3}$ Director, Indigo Women's Centre, Chennai, Tamilnadu, India \\ ${ }^{4}$ Consultant, LLM Hospital Kidangoor, Kottayam, Kerala, India
}

Received: 02 December 2016

Accepted: 09 December 2016

*Correspondence:

Dr. Shirly Kurian,

E-mail: drshrutirb@gmail.com

Copyright: () the author(s), publisher and licensee Medip Academy. This is an open-access article distributed under the terms of the Creative Commons Attribution Non-Commercial License, which permits unrestricted non-commercial use, distribution, and reproduction in any medium, provided the original work is properly cited.

\begin{abstract}
Background: To study the influence of various female prognostic factors on the outcome of pregnancy.

Methods: A Prospective observational study was conducted in the department of obstetrics and gynaecology to study the effect of different female prognostic variables in a total of 200 couples who underwent 541 cycles with controlled ovarian hyperstimulation. Variables selected for analysis were female age, menstrual history, duration of infertility, number of cycles, number dominant follicle diameter, endometrial thickness.

Results: A total of 541 IUI cycles in 200 women resulted in 65 pregnancies. The average pregnancy rates were $12 \%$ per cycle and $33 \%$ per couple. Multiple pregnancy rates were $7.6 \%$ mostly with clomiphene citrate. Endometrial thickness of more than $1 \mathrm{~mm}$, ovulation stimulation protocol with clomiphene citrate plus recombinant FSH, day of insemination after 16thday, duration of infertility of less than 5 years and treatment with less than 5 cycles has been proved as the significant prognostic variables for successful IUI. Stimulation with sequential clomiphene citrate and recombinant FSH resulted in best pregnancy rates with low multiple pregnancy rates.

Conclusions: Careful selection of subjects, appropriate controlled ovarian stimulation and intra uterine insemination lead to good pregnancy rates with low multiple pregnancy.
\end{abstract}

Keywords: Clomiphene, Endometrial thickness, Induction protocols, Recombinant FSH

\section{INTRODUCTION}

For many couples advent of a baby is the most beautiful gift of life. Infertility is defined as failure of a couple to conceive after one year of unprotected intercourse. Approximately $85 \%-90 \%$ couple conceive within one year. Infertility therefore affects $10-15 \%$ couples. ${ }^{1}$ Intra uterine insemination (IUI) is the first step in the ladder of fertility management in couples with no evidence of tubal damage or severe male factor. ${ }^{2}$ The overall success of intra uterine insemination varies, with pregnancy rates between 5 and $26 \%$ per cycle. ${ }^{3}$ IUI with controlled ovarian hyperstimulation is more effective than intra uterine insemination alone or intra cervical insemination. ${ }^{4}$ Ovarian stimulation has been shown to significantly improve the outcome in IUI cycles by two mechanisms; By increasing the number of eggs available for fertilisation and By overcoming a subtle defect in ovulatory function in ovulatory function and luteal phase. ${ }^{4}$ Pregnancy outcomes after IUI are determined by a number of factors, these factors include the use ovulation induction protocols, patient age, duration of infertility and the type of infertility. ${ }^{5}$ The need to establish how these factors can be manipulated to maximise the likelihood of pregnancy is, therefore, a reasonable question that needs a crystal clear answer. So 
the purpose of the study to evaluate the female prognostic factors influencing pregnancy rate after intrauterine insemination with controlled ovarian hyperstimulation in infertile couples.

\section{METHODS}

This prospective observational study was conducted at Department of Obstetrics and Gynaecology, Apollo Hospital, and Chennai from April 2009 to Oct 2010. The study was approved by Ethics Committee. This study included 200 couples who underwent 541 intra uterine insemination cycles, with controlled ovarian hyper stimulation and who fulfil the inclusion and exclusion criteria. The duration of infertility was defined by the time interval from beginning of unprotected intercourse until registration at the fertility centre. Detailed history of the couple include age, duration of infertility, regularity of periods, duration of contraception, sexual history, previous treatments if taken, occupation, family history.

After obtaining history general physical and systemic examination was carried out. Per speculum examination was performed and Pap smear taken if indicated. Per vaginal examination was done. Abnormal findings noted. Semen analysis done for male partner as per WHO criteria

Inclusion criteria: Women of age less than 40,negative pregnancy test, Patent fallopian tubes, Normal uterine cavity, History of Infertility $>1$ year. Men of Age $<50$ History of infertility $>1$ year, Normal semen analysis.

Exclusion criteria: Women with Previous IVF, Previous H/O PID, Previous IVF, Men with Previous H/O of Intrauterine insemination. For statistical analysis variables selected for analysis were female age, menstrual history, duration of infertility, no. of cycles, number dominant follicle diameter, endometrial thickness. All the continuous variables were represented by mean with standard deviation and it was analysed by independent sample t-test. Categorical variables were presented by frequency and percentages; it was analysed by Chi-square and Fisher exact test. Logistic regression analysis was used for multiple variable comparisons to pregnancy rate. All the analysis was done by using SPSS 14.0 version. A $\mathrm{p}$ value less than 0.05 were considered as significant.

\section{RESULTS}

A total of 541 IUI cycles in 200 women resulted in 65 pregnancies (Table 1). The number of treatment cycles varied from 1 to 8 with a mean of $2.06 \pm 1.49$ per couple. The average clinical pregnancy rate was $12 \%$ per cycle (Table 1) and the pregnancy rate was higher in first treatment cycle $(66.77 \%)$ and decreased from second cycle onwards.

The overall pregnancy rate was $33 \%$ per patient. The age range varied from 19-38 years and the average age was
$29.08 \pm 4.19$ years. The pregnancy rate in the age group $<30$ years was $33.04 \%$ in comparison to 31.76 in the age group more than 30 years $(p=0.849)$, therefore the pregnancy rate and age of women are not statistically significant.

Table 1: Clinical pregnancy per couple and per cycle.

\begin{tabular}{|lll|}
\hline Outcome & Frequency & Percentage \\
\hline Negative & 135 & 67.5 \\
\hline Positive & 65 & 32.5 \\
\hline Outcomes & No. of cycles & Percent \\
\hline Negative & 476 & 88.0 \\
\hline Positive & 65 & 12.0 \\
\hline Total & 541 & 100.0 \\
\hline
\end{tabular}

Table 2: Number of cycles.

\begin{tabular}{|lll|}
\hline No of cycles & No. of patients & Percentage \\
\hline 1 & 45 & 22.5 \\
\hline 2 & 47 & 23.5 \\
\hline 3 & 60 & 30.0 \\
\hline 4 & 27 & 13.5 \\
\hline 5 & 12 & 6.0 \\
\hline 6 & 7 & 3.5 \\
\hline 7 & 1 & .5 \\
\hline 8 & 1 & .5 \\
\hline Total & $\mathbf{2 0 0}$ & $\mathbf{1 0 0 . 0}$ \\
\hline
\end{tabular}

Table 3: Number of cycles during pregnancy.

\begin{tabular}{|llllll|}
\hline & $\begin{array}{l}\text { Clinical } \\
\text { pregnancy }\end{array}$ & N & Mean & $\begin{array}{l}\text { Std. } \\
\text { Deviation }\end{array}$ & $\begin{array}{l}\text { P } \\
\text { value }\end{array}$ \\
\hline $\begin{array}{l}\text { No. } \\
\text { of } \\
\text { cycles }\end{array}$ & Negative & 135 & 3.04 & 1.242 & $<0.001$ \\
\cline { 2 - 5 } & positive & 65 & 2.06 & 1.488 & \\
\hline
\end{tabular}

The number of patients was 102 with a period of infertility less than 5 years accounting to $51 \%$ whereas percentage of patients with a period of infertility was $34.5 \%$. Duration of infertility is a highly significant factor with maximum positive outcome when the mean duration of infertility is $4.78 \mathrm{yrs}$. Out of the 200 respondents 164 patients had regular cycles that are $82 \%$ whereas the percentage of those who had irregular cycles was $18 \%$. The pregnancy rate was $9.5 \%$ when one follicle was produced, whereas with more than 1 follicle, the rate increased to $18.1 \%$.

Most of the patients underwent less than 3 cycles (Table 2). Day of insemination is a significant factor with maximum pregnancy after 15 th day of insemination.

Among the different ovulation induction protocols maximum patients underwent ovulation induction with clomiphene citrate (202/541). The pregnancy rate increased with the number of mature follicles up to 3 , 
being significantly higher if more than one mature follicle developed and is statistically significant $(p=<0.001)$. The mean number of follicles was $1.42 \pm 0.64$. In our study the size of the follicle is not a significant variable this might be because most of the follicles are above $1.5 \mathrm{~cm}$. Insemination between day 10 and 14 resulted in a pregnancy rate of $9.9 \%$ compared to $20.4 \%$ if insemination was carried out between day 16 and 25 and it is statistically significant $(\mathrm{p}=0.003)$ (Table 3).

Table 4: Size of follicles.

\begin{tabular}{|llll|}
\hline $\begin{array}{l}\text { Sire of } \\
\text { follicles }\end{array}$ & & & \\
$1-1.5$ & 0 & 0 & 0.235 \\
$1.5-2$ & $2 / 46$ & 4.3 & \\
$2-2.5$ & $55 / 438$ & 12.6 & \\
$>2.5$ & $8 / 57$ & 14.0 & \\
\hline $\begin{array}{l}\text { Day of } \\
\text { insemination }\end{array}$ & & & \\
$10-15$ & $43 / 433$ & 9.9 & \\
$16-25$ & $22 / 108$ & 20.4 & \\
\hline $\begin{array}{l}\text { Ovulation } \\
\text { induction }\end{array}$ & & & \\
drug & & & \\
CC & & & \\
Gonal & 10 & 8.4 & \\
CC and Gonal & 5 & 26.3 & \\
\hline Endometrial & & 38.5 & \\
thickness & & & \\
0.60 & 0 & & \\
0.70 & $6 / 91$ & $6.001^{* *}$ \\
0.80 & $7 / 179$ & 3.9 & \\
0.90 & $34 / 176$ & 19.3 & \\
1.00 & $4 / 43$ & 9.3 & $<0.001^{* *}$ \\
1.10 & $11 / 35$ & 31.4 & \\
1.20 & $2 / 3$ & 66.7 & \\
\hline
\end{tabular}

Among the different ovulation induction protocols maximum number of patients underwent ovulation induction with clomiphene citrate, clomiphene citrate when combined with $\mathrm{r}$ FSH gives maximum pregnancy rate $38.5 \%$ and it is statistically significant as compared to other drugs $(\mathrm{p}=<0.001)$. Multivariate analysis of the variable shows that number of follicles, endometrial thickness, ovulation induction with clomiphene citrate and $\mathrm{rFSH}$, number of cycles and insemination after 15 th day are significant variables for better pregnancy rates.

\section{DISCUSSION}

It took almost 80 years before the first pregnancy achieved by way of intrauterine insemination was reported by Sims in $1867 .^{6}$ Intrauterine insemination is defined as direct transfer of motile spermatozoa into the uterine cavity after semen preparation and concentration in a small volume of medium. ${ }^{7}$ The pregnancy rate (PR) after intra uterine insemination has varied between 9 and $21 \%$ per cycle. ${ }^{8-10}$ Insemination as a low cost and patient friendly method still has a definitive role in the field of infertility treatment. A recent metaanalysis evaluated the effectiveness of intrauterine insemination showed PR of $7 \%$ with Clomiphene citrate and $12 \%$ with FSH and MPR being $13 \%$ with intra uterine insemination ${ }^{11}$. In planning infertility treatment, the most effectiveness of the treatment and MPRs should be considered. Now days when IVF and ICSI are widely available, over treatment should be avoided and intra uterine insemination appears be a more cost effective option than immediate IVF. ${ }^{12}$ It has been demonstrated that three cycles of intra uterine insemination result in the same cumulative pregnancy rate as IVF and intra uterine insemination is more cost effective as regards unexplained infertility \& moderate male factor infertility. ${ }^{13}$

Endometriosis decreased the effectiveness of controlled ovarian hyper stimulation and intra uterine insemination by half in the treatment of persistent unexplained infertility. ${ }^{14}$ Endometrial thickness of more than $1 \mathrm{~mm}$, ovulation stimulation protocol with clomiphene citrate plus recombinant $\mathrm{FSH}$, day of insemination after $16^{\text {th }}$ day, duration of infertility of less than 5 years and treatment with less than 5 cycles has been proved as the significant prognostic variables for successful IUI. Farimani M et al 2007 shows a PR of $1.4 \%$ when ET $10 \mathrm{~mm}$. and $6.8 \%$ when $<10 \mathrm{~mm}^{15}$

Stimulation with sequential clomiphene citrate and recombinant FSH resulted in best pregnancy rates with low multiple pregnancy rates. In this protocol clomiphene citrate $100 \mathrm{mg}-150 \mathrm{mg}$ administered from Day 3 to Day 7 inj FSH 75 IU is given on Day 3, 5, 7. Trans Vaginal scan done on day 2 (basal) and from Day 8 thereafter to monitor the follicles thereafter.

Jee $\mathrm{BC}$ et al compared the pregnancy rates between letrozole and clomiphene citrate+ FSH in intra uterine insemination. The study indicated that matured follicles were comparatively lower in letrozole group as compared to clomiphene citrate + FSH group $(3.2 \pm 1.7$ Vs $5.6 \pm$ 2.4).No significant difference in endometrial thickness and pregnancy rates(18.2 vs $25 \%)$. There was no significant difference in both the groups. ${ }^{16}$ Moreover letrozole is banned for this indication.

Zahrat et al showed no significant difference in the pregnancy rates of the different treatment group clomiphene citrate vs HMG Vs clomiphene citrate+ HMG (pr 17\% Vs $7.1 \%$ Vs 23\%). ${ }^{17}$ Farimani $\mathrm{M}$ et al, also did not shown significant differences in the pregnancy rates between $\mathrm{FSH}$ and clomiphene citrate+ FSH(PR $15.7 \%$ vs $11.3 \%$ ) Clomiphene citrate+ Gonadotropins has the advantages of being more cost effective as the dose of gonadotropins is reduced. ${ }^{2}$ Nowadays when the costs of health care are limited, intrauterine insemination can hold its place as a low cost method of infertility treatment. Conclusively with careful selection of subjects, appropriate controlled ovarian stimulation and intra uterine insemination, good 
pregnancy rates with low multiple pregnancy rates can be achieved.

So it was concluded that the primary goal of the clinician is to choose the most appropriate treatment with least invasive technology for an individual couple. In the present study average pregnancy rates was $12 \%$ per cycle and $33 \%$ per couple. Multiple pregnancy rates was $7.6 \%$ mostly associated with clomiphene citrate. Endometrial thickness of more than $1 \mathrm{~mm}$, ovulation stimulation protocol with clomiphene citrate plus recombinant FSH, day of insemination after $16^{\text {th }}$ day, duration of infertility of less than 5 years and treatment with less than 5 cycles has been proved as the significant prognostic variables for successful IUI. Female age, menstrual history were not significant prognostic indicators .Stimulation with sequential clomiphene citrate and recombinant FSH resulted in best pregnancy rates with low multiple pregnancy rates.

\section{ACKNOWLEDGEMENTS}

We want to acknowledge the Head of the Department Dr. Sarat Battina for providing us with all facilities and equipment's for the completion of this study.

\section{Funding: No funding sources}

Conflict of interest: None declared

Ethical approval: The study was approved by the Institutional Ethics Committee

\section{REFERENCES}

1. Mosher WD, Pratt WF. Fecundity and infertility trends in U. S. Fertil and Steril. 1992;56:92.

2. Fariman M, Amiri I. Analysis of prognostic factors for successful outcome in patients undergoing IUI. Acta Medica Iranica. 2007;45(2):101-6.

3. Allen NC, Maxon WS, Rogers BJ. Intra uterine insemination a critical review. Fertil Steril. 1985;44(5):569-80.

4. Steures P. Homps Intra-uterine insemination with controlled ovarian hyperstimulation vs expectant management for couples with unexplained subfertility and intermediate prognosis: a randomnised clinical trial. Lancet. 2006;368:216-21.
5. Viahos ZY. Impact of semen characteristics on success of IUA. J Assist reproduction Genetics. 2004;21:143-8.

6. Cohlen BJ. Controlled ovarian hyperstimulation and IUI for treating male subfertility: a controlled study. Human Reproduction, 1998;13:1553-8.

7. Aitken RJ. Significance of reactive oxygen species and anti-oxidants in defining the efficacy of sperm preparation techniques. J Androl. 2000;9:367-76.

8. Claman P, Wilkie V. Timing IUI either 33 or 39 hours after administration of hCG yield the same pregnancy rates as after super ovulation. Ferti Steril. 2004;82:13-6.

9. Hamilton J, Latarche E, Gillot C, Lower A. IUI result are not affected by HSG is used as the sole test of tubal patency. Fertile Steril. 2003;80:165-71.

10. Iberico G, Vioque J, Ariza N, Lozano JM, Roca M, Llacer J. Analysis of factors influencing pregnancy rates in homologous IUI. Fertil Steril. 2004;81:130813.

11. ESHRE Capri Workshop Group. Intrauterine insemination. Hum Reprod Update. 2009;15(3):26577.

12. Garceau L, Henderson J, Dacis LJ. Economic implications of assisted reproductive techniques: A systematic review. Human Rep. 2002;17:3090-109.

13. Goverde AJ, Mc-Donnell J. IUI or IVF in idiopathic sub-fertility and male sub-fertility: a randomized trial and cost effective analysis. Lancet. 2000;355:13-8.

14. Hughes EG. The Effectiveness of ovulation induction in intra-uterine insemination in the treatment of persistant infertility: a meta-analysis Human reproduction. 1997;12:1865-72.

15. Farimani M, Amiri I. Analysis of prognostic factors for successful outcome in patients undergoing IUI. Acta Medica Iranica. 2007;45(2):101-6.

16. Jee BC. Use of Letrozal vs CC combined with Gonadotropins in IUI a pilot study. Fertil Steril. 2006;85(6):1774-7.

17. Basiral Z, Seddigeh. Prognostics factors of pregnancy in 500 cases of IUI in Babol Northern Iran. Fertil Steril. 1989;21(4):35-9.

Cite this article as: Kurian $\mathrm{S}$, Mathew $\mathrm{J}$, Battina $\mathrm{S}$, Nisha BS. Evaluation of female prognostic factors influencing pregnancy rate after intrauterine insemination with controlled ovarian hyper stimulation in infertile couples in a tertiary care hospital. Int J Reprod Contracept Obstet Gynecol 2017;6:29-33. 